\title{
Glycolysis inhibition via mTOR suppression is a key step in cardamonin-induced autophagy in SKOV3 cells
}

\author{
Daohua Shi ${ }^{* \dagger} \mathbb{B}$, Di Zhao ${ }^{\dagger}$, Peiguang Niu, Yanting Zhu, Jintuo Zhou and Huajiao Chen
}

\begin{abstract}
Background: Autophagy occurs in cells that undergoing nutrient deprivation. Glycolysis rapidly supplies energy for the proliferation of cancer cells. Cardamonin inhibits proliferation and enhances autophagy by mTORC1 suppression in ovarian cancer cells. Here, we investigate the relationship between cardamonin-triggered autophagy and glycolysis inhibition via mTORC1 suppression.

Methods: Treated with indicated compounds, ATP content and the activity of hexokinase (HK) and lactate dehydrogenase (LDH) were analyzed by the assay kits. Autophagy was detected by monodansylcadaverin (MDC) staining. The relationship between cardamonin-triggered autophagy and glycolysis inhibition via mTORC1 suppression was analyzed by Western blot.

Results: We found that cardamonin inhibited the lactate secretion, ATP production, and the activity of HK and LDH. The results demonstrated that cardamonin enhanced autophagy in SKOV3 cells, as indicated by acidic compartments accumulation, microtubule-associated protein 1 Light Chain 3-II (LC3-II) and lysosome associated membrane protein 1 up-regulation. Our results showed that the activation of mTORC1 signaling and the expression HK2 were reduced by cardamonin; whereas the phosphorylation of AMPK (AMP-activated protein kinase) was increased. We also confirmed that the AMPK inhibitor, Compound C, reversed cardamonin-induced upregulation of LC3-II.
\end{abstract}

Conclusion: These results suggest that cardamonin-induced autophagy is associated with inhibition on glycolysis by down-regulating the activity of mTORC1 in ovarian cancer cells.

Keywords: AMPK, Autophagy, Cardamonin, Glycolysis, mTOR

\section{Background}

Autophagy is a catabolic membrane-trafficking process that mediates the degradation of intracellular material within lysosomes. The cytoplasmic contents are degraded into free nucleotides, amino acids and fatty acids, which are reused by the cell to maintain macromolecular synthesis and to fuel energy production [1]. Autophagy serves as either tumor suppressor or protector in different conditions. It degrades damaged mitochondria and other cell organelles to maintain cell survival. However, excessive autophagy leads to progressive consumption of cellular components, and ultimately induces cell death

\footnotetext{
* Correspondence: shidh@yeah.net

${ }^{\dagger}$ Daohua Shi and Di Zhao contributed equally to this work.

Department of Pharmacy, Fujian Provincial Maternity and Children's Hospital, Affiliated Hospital of Fujian Medical University, 18 Daoshan Road, Fuzhou 350001, Fujian, China
}

$[2,3]$. Increasing evidence indicates that induction of autophagy inhibits tumorigenesis and cancer progression, especially in certain ovarian cancers which exhibits lack of autophagy [4].

Autophagy is an evolutionarily conserved mechanism of adaptation to microenvironmental conditions, such as metabolism inhibition. It ensures the survival and proliferation of cancer cells under hypoxia and energy starvation [5]. Several signaling pathways capacitate cancer cells to acquire and metabolize nutrients in a manner conducive to proliferation rather than efficient ATP production. Cancer cells produce energy via the conversion of glucose into lactate, despite the presence of oxygen, a process known as aerobic glycolysis. It generates the precursors needed for the synthesis of lipids and nucleotides [6]. Therefore, glycolysis is another evolutionarily mechanism which 
provides materials for growth and proliferation of cancer cells. Moreover, production of lactic acid can stimulate the invasion and metastasis of cancer cells [7]. Here, we postulate that glycolysis inhibition results in energy deprivation and further triggers autophagy, which ultimately leads to autophagic cell death.

The mammalian target of rapamycin (mTOR) is a key regulator of protein synthesis and cell proliferation. It considered to be an appealing therapeutic target. Makinoshima et al. indicates that mTORC1 regulates glucose uptake, glycolysis and lipid biosynthesis in cancer cells [8]. And mTOR inhibition contributes to the initiation of autophagy even in the presence of sufficient nutrients and growth hormones. Inhibition on the mTOR/S6K1 pathway triggered caspase-dependent and -independent cell death in lymphoma cells by inhibition of glycolysis and induction of autophagy $[9,10]$.

Cardamonin $\left(2^{\prime}, 4^{\prime}\right.$-dihydroxy-6'-methoxy-chalcone) is the main chalcone found in large amounts of cardamom spice (fruits of Amomum subulatum Roxb.) and other medicinal plants of Zingiberaceae family, such as Alpinia katsumadae Hayata [11]. Cardamonin appears to have anti-inflammatory, antineoplastic, vasorelaxant and anti-infectious properties which benefit for the potential health applications [12]. Cardamonin inhibits the proliferation and metastasis of various cancer cells [13-15]. In our previous studies, we demonstrate that the antitumor effect of cardamonin dependents on mTOR inhibition [16, 17]. Recently, we find that the autophagy induction is account for the antiproliferative activity of cardamonin [18]. Also, cardamonin plays an important role in glucose metabolism. It eliminates the negative feedback of mTOR/S6K1 on the insulin-signaling pathway and increases glucose metabolism in insulin resistant vascular smooth muscular cells $[14,17,19]$.

In the present study, we aim to explore the mechanism of cardamonin on autophagy. The relationship between cardamonin-triggered autophagy and glycolysis inhibition via mTORC1 suppression is investigated in SKOV3 cells. It will provide a promising therapeutic agent for ovarian cancer.

\section{Methods}

\section{Cells and reagents}

Human ovarian cancer SKOV3 cells were obtained from Wuhan boster biological engineering co., LTD (Wuhan, China). Cardamonin, rapamycin, 2-deoxy-D-glucose (2-DG) and Compound C (an AMP-activated protein kinase (AMPK) inhibitor) were purchased from Sigma-Aldrich Chemical Co (St. Louis, MO, USA). The assay kits of ATP, lactate, hexokinase (HK) and lactate dehydrogenase (LDH) were purchased from Nanjing Jiancheng Bioengineering Institute (Nanjing, China). The BCA protein assay kit and antibodies for mTOR, p-mTOR (Ser2448), S6K1, p-S6K1
(Thr389), AMPK, p-AMPK (Ser172), LC3, LAMP1, HK2 and actin were obtained from Cell Signaling Technology (Beverly, MA, USA).

\section{Cell culture}

Human ovarian cancer SKOV3 cells were grown at $37^{\circ} \mathrm{C}$ in McCoy's 5A supplemented with $10 \%$ fetal bovine serum (Grand Island, NY, USA), $100 \mathrm{U} \cdot \mathrm{mL}^{-1}$ penicillin and $100 \mu \mathrm{g} \cdot \mathrm{mL}^{-1}$ streptomycin in a humidified $5 \% \mathrm{CO}_{2}$ atmosphere.

\section{Measurement of lactate}

Cells were implanted at a density of $2 \times 10^{5}$ cells/well in 6 well plates and cultured for $24 \mathrm{~h}$, then the cells were treated with cardamonin $(5,10,20 \mu \mathrm{M})$, rapamycin $(0.1 \mu \mathrm{M})$, and 2-DG (10 mM) for another $12,24,36,48,60 \mathrm{~h}$, respectively. The media was collected and centrifugated $(8000 \mathrm{~g}, 10 \mathrm{~min})$ for lactate assay according to the manufacturer's protocol of Lactate Assay Kits, respectively. The content of lactate was normalized to cell numbers. The inhibitory effect of cardamonin on lactate secretion at $24 \mathrm{~h}$ is similar to $12 \mathrm{~h}$ in some groups. Compared with 12 and $24 \mathrm{~h}$, the inhibitory effect of cardamonin is significantly increased at 36, 48 and $60 \mathrm{~h}$, respectively. Therefore, we chose the $24 \mathrm{~h}$ for the statistical analysis.

We have investigated the antiproliferation effect of cardamonin in various cancer cells. It demonstrated that the efficiency-concentration ranged from $5 \mu \mathrm{M}$ to $30 \mu \mathrm{M}$ $[13,15,16]$. In the present study, the inhibitory effect of cardamonin $(5,10$ and $20 \mu \mathrm{M})$ on the lactate secretion was measured in SKOV3 cells. In order to investigate the further mechanism of cardamonin on glycolysis, we indicated $5,20 \mu \mathrm{M}$ or $20 \mu \mathrm{M}$ of cardamonin for the following experiments.

\section{Determination of content of ATP and activity of HK and LDH}

Treated with indicated drugs as described above, the cells were washed twice with ice cold PBS and harvested with $0.25 \%$ trypsogen. The cell suspension was washed with ice cold PBS for three times. Then $300 \mu \mathrm{L}$ hot distilled water was added to the cells and the mixture was placed in a hot water bath $\left(90 \sim 100^{\circ} \mathrm{C}\right)$ for homogenized broken following a boiling water bath for $10 \mathrm{~min}$. At last the ATP was extract from the mixture for $1 \mathrm{~min}$. The ATP absorbance values were measured with the multi-plate reader at $636 \mathrm{~nm}$. Then the cells were crushed with homogenate in ice cold water for HK and LDH activity assay, followed by centrifugation $(10,000 \mathrm{~g}, 10 \mathrm{~min})$. The protein content was measured by the BCA assay kit. The ATP content and HK, LDH activity were normalized to total protein. The prepared reagent was pre-warmed at $37^{\circ} \mathrm{C}$ for $10 \mathrm{~min}$, and then $50 \mu \mathrm{L}$ of liquid sample and $960 \mu \mathrm{L}$ of reagent were immediately mixed in a tube to start the reaction. The absorbance at $340 \mathrm{~nm}$ 
(optical path: $0.5 \mathrm{~cm}$ ) was recorded after $30 \mathrm{~s}$ (OD1) using a Spectrophotometer. Subsequently, the liquid was transferred back to the previous tube and warmed in a $37^{\circ} \mathrm{C}$ water bath for $2 \mathrm{~min}$. The absorbance was measured again under the same conditions and denoted as OD2. The HK activity was calculated by the following formula according to manufacturer's instructions:

$$
\begin{aligned}
\mathrm{HK} \text { activity }(\mathrm{U} / \text { gprot })= & (\mathrm{OD} 2-\mathrm{OD} 1) / 6.22 \times(1.01 / 0.05) \\
& \div \mathrm{C}(\text { protein concentration })
\end{aligned}
$$

$50 \mu \mathrm{L}$ of liquid sample and $300 \mu \mathrm{L}$ of reagent were immediately mixed in a tube to start the reaction. The tube was cultured at $37^{\circ} \mathrm{C}$ water bath for $15 \mathrm{~min}$. And then another reagent was added in the same tube and cultured at $37^{\circ} \mathrm{C}$ water bath for $15 \mathrm{~min}$. At last $2.5 \mathrm{~mL} 0.4 \mathrm{M} \mathrm{NaOH}$ solution was added in the mixture and cultured at room temperature for $3 \mathrm{~min}$. The absorbance at $440 \mathrm{~nm}$ (optical path: $1 \mathrm{~cm}$ ) was recorded using a Spectrophotometer. The LDH activity was calculated by the following formula according to manufacturer's instructions:

$\mathrm{LDH}$ activity $(\mathrm{U} /$ gprot $)=\left(\mathrm{OD}_{\text {sample }} 1 P T-\mathrm{OD}_{\text {control }}\right) /\left(\mathrm{OD}_{\text {standard }}-\mathrm{OD}_{\text {control }}\right)$ $\times 2 \mathrm{mM} \div \mathrm{C}$ (protein concentration)

\section{Detection of autophagosome}

Cells were cultured in 6-well plates $\left(0.3 \times 10^{6} /\right.$ well $)$ for $24 \mathrm{~h}$ and then treated with cardamonin $(5,20 \mu \mathrm{M})$, rapamycin $(0.1 \mu \mathrm{M})$, and 2-DG $(10 \mathrm{mM})$ for another $48 \mathrm{~h}$. Cells were washed with ice cold PBS twice and then incubated with monodansylcadaverin (MDC, $0.05 \mathrm{mM}$ ) at room temperature in darkness for $30 \mathrm{~min}$. Then the cells were washed twice with PBS and observed by fluorescence microscope. The fluorescent intensity of MDC stain was calculated by the ImageJ software.

\section{Detection of protein expression}

Cells were cultured in $100 \mathrm{~mm}$ dishes $\left(2.2 \times 10^{6} /\right.$ dish $)$. Treated with drugs for $48 \mathrm{~h}$, cells were collected and washed twice with cold PBS, and then lysed in RIPA and centrifuged to collect the supernatant. The protein concentration was measured by a BCA assay kit. $40-50 \mu \mathrm{g}$ protein was separated on $8-12 \%$ SDS-PAGE and transferred onto a polyvinylidene fluoride membrane (Invitrogen, Carlsbad, CA, USA). After blocking the non-specific site with bovine serum albumin, the membrane was incubated with primary antibody $(1,1000$ or 1800) at $4{ }^{\circ} \mathrm{C}$ overnight, and then incubated for $60 \mathrm{~min}$ with a secondary antibody (anti-rabbit IgG, horseradish peroxidase-linked antibody; \#7074; Cell Signaling Technologies, Beverly, MA, USA; dilution, 1:2000) at room temperature, respectively. Immunoreactive proteins were detected by HRP-ECL chemiluminescence reagents.

\section{Statistical analysis}

All data were expressed as mean $\pm \mathrm{SD}$. Differences between groups were evaluated by the Student's $t$ test or one way ANOVA followed by Dunnett's multiple comparison test. $p<0.05$ was considered as statistically significant.

\section{Results}

\section{Cardamonin suppressed the glycolysis}

Glycolysis is characterized with the conversion of glucose into lactate [20]. We measured the content of lactate to assess the inhibitory effect of cardamonin on glycolysis. As shown in Fig. 1, the lactate secretion was significantly inhibited by cardamonin in a dose- and time-dependent manner by cardamonin in SKOV3 cells. Treated with indicated drugs for $48 \mathrm{~h}$, the inhibitory effect of cardamonin on lactate secretion is almost the strongest. Similarly, the intracellular ATP content was decreased by cardamonin in a dose-dependent manner at $48 \mathrm{~h}$. Interestingly, the activity of HK and LDH was also reduced by cardamonin and rapamycin, while 2-DG had no effect on these kinases (Table 1).

\section{Cardamonin induced cell autophagy}

The autophagy level was confirmed by MDC staining and LC3-II detection in SKOV3 cells. Treated with cardamonin and rapamycin, the fluorescent intensity of MDC stain was significantly elevated (Fig. 2a and b); and the protein level of LC3-II and LAMP1 was increased. As a glycolysis inhibitor, 2-DG also induced autophagy (Fig. 2c-e).

Cardamonin inhibited the expressions of p-S6K1, p-mTOR, HK2 and increased p-AMPK

Since the antitumor activity of cardamonin is correlates with mTOR, the activity of mTOR signaling is investigated. As expected, cardamonin inhibited phosphorylation

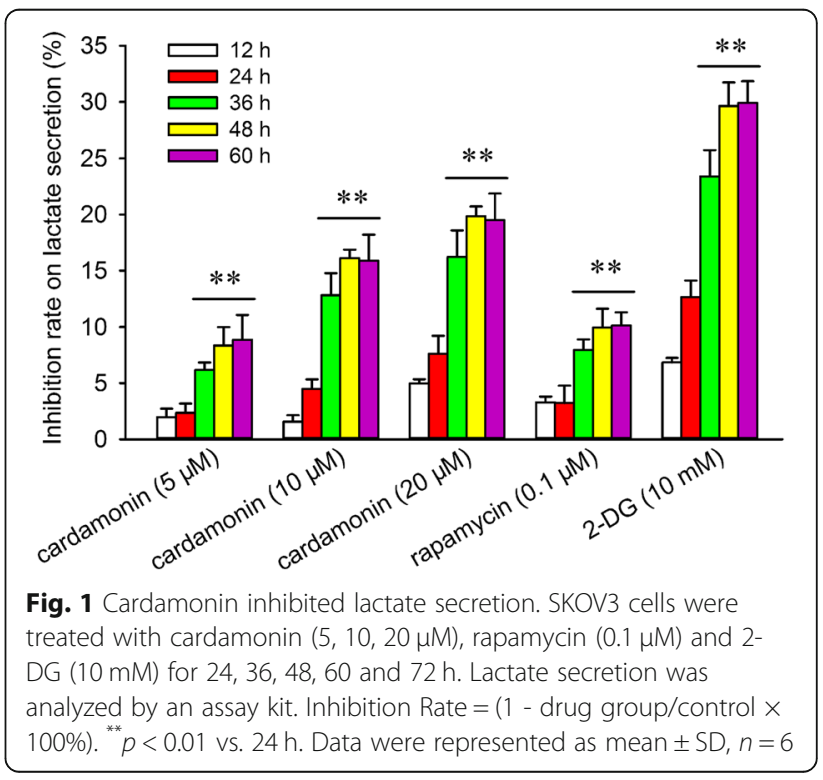


Table 1 Cardamonin inhibited ATP production and the activity of HK and LDH

\begin{tabular}{llll}
\hline & ATP $(\mu \mathrm{moL} / \mathrm{g}$ prot $)$ & HK $(\mathrm{U} / \mathrm{g}$ prot $)$ & LDH (U/g prot) \\
\hline Control & $94.05 \pm 0.94$ & $43.63 \pm 3.82$ & $307.28 \pm 6.71$ \\
Cardamonin $(5 \mu \mathrm{M})$ & $87.69 \pm 0.79^{* *}$ & $35.58 \pm 3.34^{* *}$ & $292.94 \pm 5.56^{* *}$ \\
Cardamonin $(10 \mu \mathrm{M})$ & $50.98 \pm 1.67^{* *}$ & $33.95 \pm 3.04^{* *}$ & $276.62 \pm 4.04^{* *}$ \\
Cardamonin $(20 \mu \mathrm{M})$ & $29.87 \pm 1.31^{* *}$ & $27.46 \pm 3.60^{* *}$ & $225.58 \pm 7.50^{* *}$ \\
Rapamycin $(0.1 \mu \mathrm{M})$ & $56.07 \pm 1.47^{* *}$ & $34.14 \pm 4.90^{* *}$ & $286.46 \pm 8.68^{* *}$ \\
2-DG $(10 \mathrm{mM})$ & $24.33 \pm 1.90^{* *}$ & $43.72 \pm 3.12$ & $302.43 \pm 4.20$ \\
\hline
\end{tabular}

SKOV3 cells were treated with cardamonin $(5,10,20 \mu \mathrm{M})$, rapamycin $(0.1 \mu \mathrm{M})$ and 2-DG $(10 \mathrm{mM})$ for $48 \mathrm{~h}$, respectively. ATP content and the activity of HK and LDH were analyzed by the assay kits, respectively. ${ }^{* *} p<0.01$ compared to control. Data were represented as mean $\pm S D, n=6$

2-DG 2-deoxy-D-glucose, $H K$ hexokinase, $L D H$ lactate dehydrogenase

of mTOR (Ser2448) and its downstream target S6K1 (Thr389). As an energy sensor, AMPK is activated by decreased ATP production. The expression of $\mathrm{p}$-AMPK and HK2 was markedly increased when treated with cardamonin $(20 \mu \mathrm{M})$, rapamycin or 2-DG for $48 \mathrm{~h}$, respectively. This result was in accordance with the glycolysis inhibition described above (Fig. 3).
The activity of AMPK was associated with autophagy induction by cardamonin

Next we investigated whether cardamonin-induced autophagy was correlated with glycolysis inhibition. The phosphorylation of AMPK was increased by cardamonin, which was significantly inhibited when combined with the AMPK inhibitor, Compound C.

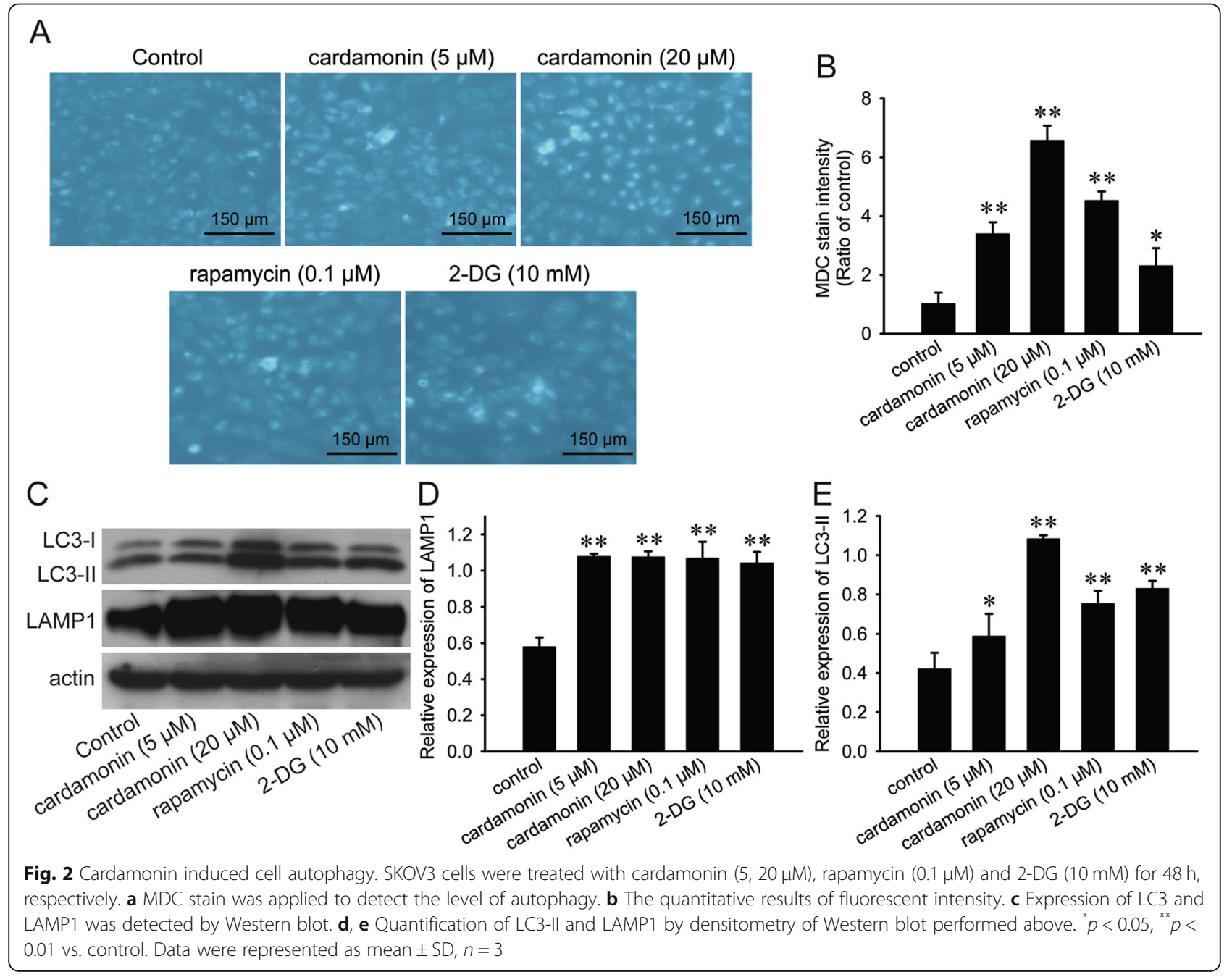




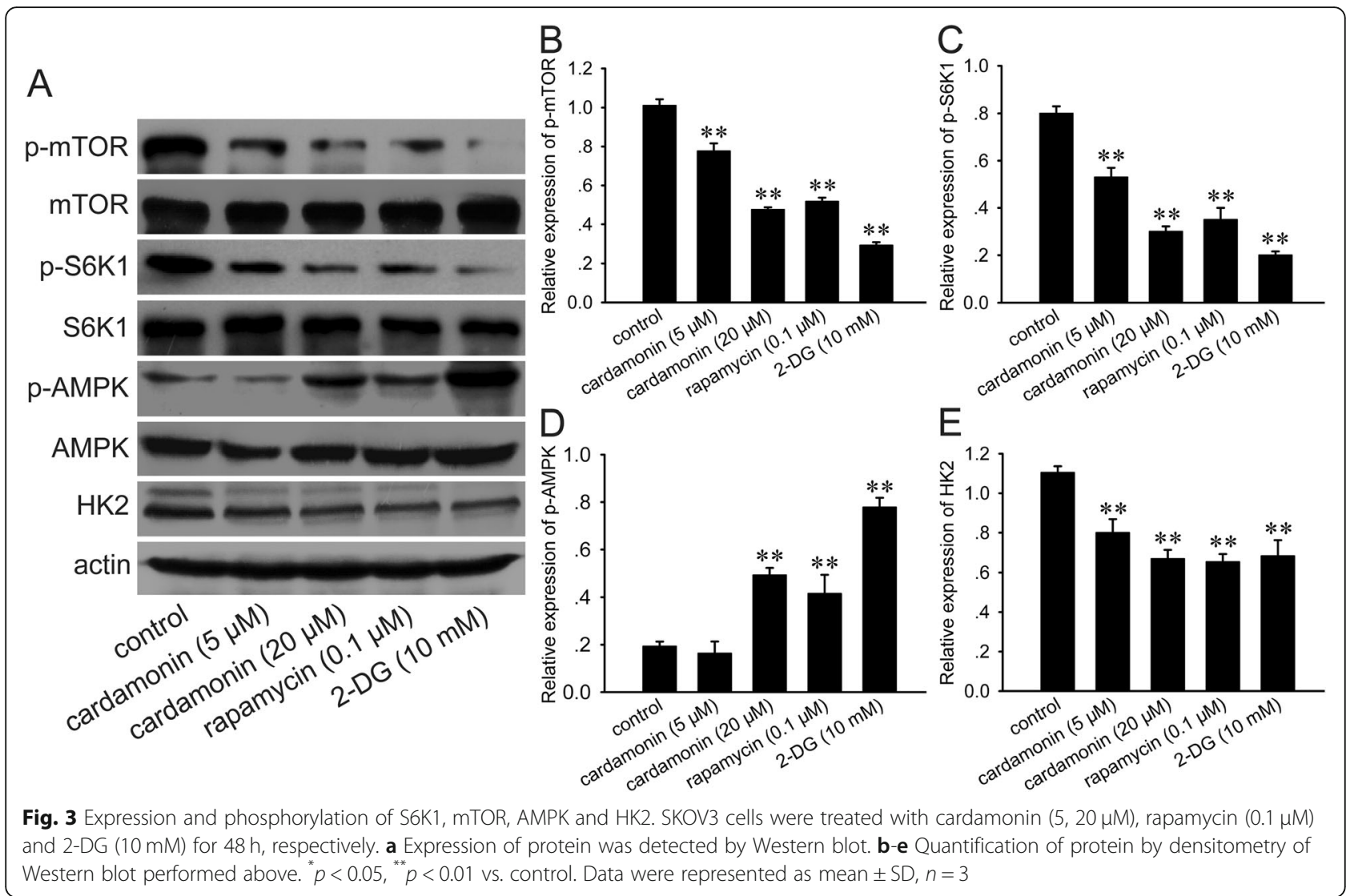

Similarly, the cardamonin-induced expression of LC3-II was reduced by Compound C (Fig. 4).

\section{Discussion}

Autophagy attempts to maintain/restore metabolic homeostasis through digesting the damaged or aged organelles. Recently, Muilenburg et al. have shown that autophagy is a potential strategy for ovarian cancer therapy [21]. Dasatinib can induce cell death through autophagy in ovarian cancer [22]. In addition, increased expression of autophagy protein PEA-15prolonged the life of ovarian cancer patients [23]. Therefore, autophagy provides new ideas for the treatment of ovarian cancer.

LC3 is essential for the elongation of autophagosome membrane. LC3-I conjugates phosphatidylethanolamine to form LC3-II, and LC3-II presents on the outer and inner surfaces of the autophagosome. LAMP1 is a structural protein of the lysosome membrane, which is also considered as an indicator for autophagy [24]. In our present study, the expression of LC3-II and LAMP1 was increased by cardamonin, as well as the acidic autophagy vacuoles stained by MDC. These effects of cardamonin were consistent with that of other similar flavonoids, such as genistein and baicalein $[25,26]$. Also, the glycolysis inhibitor 2-DG and mTOR inhibitor rapamycin increased autophagy in SKOV3 cells in the present study. The mechanism of rapamycin and 2-DG on autophagy induction has been demonstrated in other studies. Rapamycin specifically inhibits mTORC1 while that of 2-DG is related to glycometabolism inhibition [27, 28].

When nutrients are deprived, autophagy is enabled by impaired cellular ATP production. As the key point of energy metabolism, glycometabolism plays a unique role in maintaining ovarian cancer cell growth [29-31]. HK is involved in the glycolysis pathway in cancer cells [32]. HK catalyzes the first step of glycolysis. It phosphorylates glucose to glucose-6-phosphate. HK2 is a predominant isoform of $\mathrm{HK}$, which is upregulated in ovarian cancer [33]. It demonstrated that 20(S)-Rg3 inhibited the Warburg effect by targeting STAT3/HK2 pathway in ovarian cancer cells [34]. LDH sustains the glycolysis through catalyzing the regeneration of nicotinamide adenine dinucleotide from reduced nicotinamide adenine dinucleotide in cancer cells [35]. It demonstrates that various flavonoids, including luteolin, wogonin, etc. can inhibit glycolysis [36, 37]. In our study, cardamonin inhibited the activity of HK2 and LDH. It contributes to the glycolysis inhibitory effect of cardamonin. The results were similar with 2-DG, a glucose analog that competitively phosphorylated by $\mathrm{HK}$ with glucose and further inhibits glycolysis [28, 38]. It indicated that cardamonin inhibits glycolysis induced energy production. 


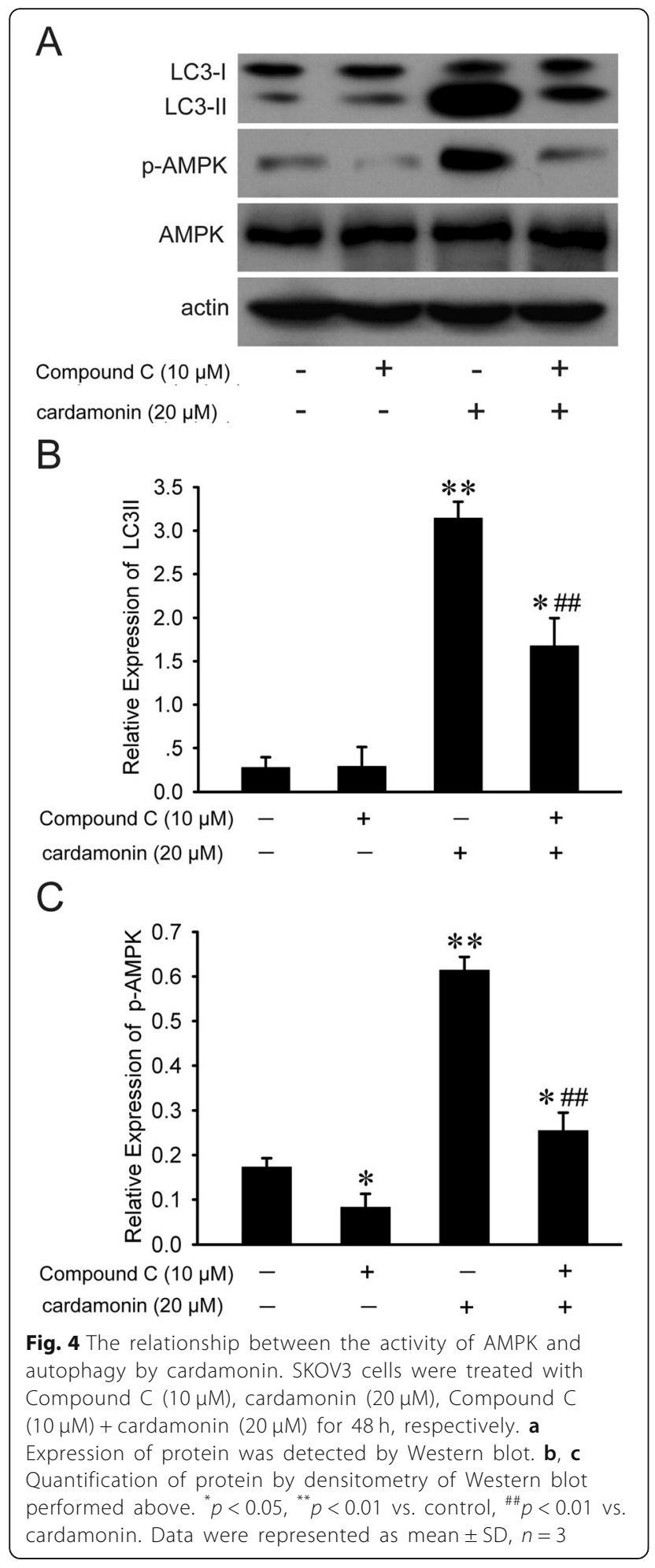

Interestingly, we found that both cardamonin and 2-DG decreased the relative protein expression of HK2. However, only cardamonin but not 2-DG inhibited the activity of HK. The underling mechanism needs to be further illustrated.
mTOR regulates cell growth and metabolism. There exists two different mTOR complexes called mTOR complex 1 (mTORC1) and mTORC2 [39]. The activity of glycolytic enzyme is elevated in an mTORC1-dependent manner in the TSC-deficient cells. Activated mTOR stimulates HIF- $1 \alpha$ and coordinately induces the expression of several enzymes for glucose metabolism, including glucose transporters, $\mathrm{HK}$ and LDH $[32,40]$. It demonstrates that mTORC1 inactivation by rapamycin is critical for glucose metabolism [41, 42]. Rapamycin binds to the FK506-binding protein of 12 $\mathrm{kDa}$ (FKBP12) and inhibits the activity of mTORC1 [43]. Our previous study showed that cardamonin had a similar effect with rapamycin on mTOR and its downstream substrates, but this effect was not dependent on FKBP12 [17]. Here, we also observed that cardamonin decreased the phosphorylation of mTOR and S6K1. Therefore, it suggested that the inhibition of glycolysis by cardamonin was regulated by mTORC1 suppression.

AMPK plays an important role in adaptive responses to reduced energy production. In response to nutrition deficiency, accumulation of AMP binding to AMPK $\gamma$ subunit leads to activation of AMPK $[44,45]$. In our present result, cardamonin activated AMPK, which was similar with 2-DG. In order to clarify the activation of AMPK partly results in autophagy induction, we added the Compound $\mathrm{C}$ in the experiment. Cardamonin-induced autophagy was reduced by Compound $\mathrm{C}$. All these findings suggested that autophagy stimulation by cardamonin was involved in glycolysis inhibition mediated AMPK activation.

\section{Conclusion}

Cardamonin exhibits antiproliferation activity in various cancer cells. This study also demonstrates that cardamonin-induced autophagy is associated with glycolysis inhibition via mTOR inhibition in SKOV3 cells. Our increased understanding about the mechanism of antitumor effect of cardamonin provides important evidences for further development of cardamonin as a novel therapeutic drug for ovarian cancer.

\section{Abbreviations}

2-DG: 2-deoxy-D-glucose; AMPK: AMP-activated protein kinase;

HK2: Hexokinase 2; LAMP1: Lysosome associated membrane protein 1; LC3II: Microtubule-associated protein 1 Light Chain 3-Il; LDH: Lactate dehydrogenase; MDC: Monodansylcadaverin; mTOR: Mammalian target of rapamycin; mTORC1: Mammalian target of rapamycin complex 1; S6K1: Ribosome S6 kinase 1

\section{Acknowledgements}

Not applicable.

\section{Funding}

This work was supported by the Natural Science Foundation of Fujian Province [grant numbers $2016 \mathrm{~J} 01492$ and 2017 J01234], Innovative Medical Foundation and Youth Foundation of Fujian Provincial Health and Family Planning Commission [grant number 2016-CX-13 and 2017-118, 2017-1-19], China. 


\section{Availability of data and materials}

The datasets used and/or analyzed during the current study available from the corresponding author on reasonable request.

\section{Authors' contributions}

DS conceived and designed the experiments; DZ performed the experiments; $Y Z$ and JZ analyzed the data; $\mathrm{HC}$ participated in the detection of protein expression. PN, DZ and DS drafted the manuscript. All authors have been involved in critically revising the manuscript and have approved the final version.

\section{Ethics approval and consent to participate}

Not applicable.

\section{Consent for publication}

Not applicable.

\section{Competing interests}

The authors declare that they have no competing interests.

\section{Publisher's Note}

Springer Nature remains neutral with regard to jurisdictional claims in published maps and institutional affiliations.

\section{Received: 4 July 2018 Accepted: 20 November 2018}

\section{Published online: 04 December 2018}

\section{References}

1. Roberts DJ, Miyamoto S. Hexokinase II integrates energy metabolism and cellular protection: Akting on mitochondria and TORCing to autophagy. Cell Death Differ. 2015;22(2):248-57.

2. Choi KS. Autophagy and cancer. Exp Mol Med. 2012:44(2):109-20.

3. Thorburn A, Thamm DH, Gustafson DL. Autophagy and cancer therapy. Mol Pharmacol. 2014:85(6):830-8.

4. Peracchio C, Alabiso O, Valente $\mathrm{G}$, Isidoro C. Involvement of autophagy in ovarian cancer: a working hypothesis. J Ovarian Res. 2012;5(1):22.

5. Jangamreddy JR, Jain MV, Hallbeck AL, Roberg K, Lotfi K, Los MJ. Glucose starvation-mediated inhibition of salinomycin induced autophagy amplifies cancer cell specific cell death. Oncotarget. 2015;6(12):10134-45.

6. Courtnay R, Ngo DC, Malik N, Ververis K, Tortorella SM, Karagiannis TC. Cancer metabolism and the Warburg effect: the role of HIF-1 and PI3K. Mol Biol Rep. 2015;42(4):841-51.

7. Cantor JR, Sabatini DM. Cancer cell metabolism: one hallmark, many faces. Cancer Discov. 2012;2(10):881-98

8. Makinoshima H, Takita M, Saruwatari K, Umemura S, Obata Y, Ishii G, et al. Signaling through the phosphatidylinositol 3-kinase (PI3K)/mammalian target of Rapamycin (mTOR) Axis is responsible for aerobic glycolysis mediated by glucose transporter in epidermal growth factor receptor (EGFR)-mutated lung adenocarcinoma. J Biol Chem. 2015;290(28):17495-504.

9. Xu RH, Pelicano H, Zhang H, Giles FJ, Keating MJ, Huang P. Synergistic effect of targeting mTOR by rapamycin and depleting ATP by inhibition of glycolysis in lymphoma and leukemia cells. Leukemia. 2005;19(12):2153-8.

10. Gu L, Xie L, Zuo C, Ma Z, Zhang Y, Zhu Y, et al. Targeting mTOR/p70S6K/ glycolysis signaling pathway restores glucocorticoid sensitivity to 4E-BP1 null Burkitt lymphoma. BMC Cancer. 2015;15:529.

11. de Castro CC, Costa PS, Laktin GT, de Carvalho PH, Geraldo RB, de Moraes J, et al. Cardamonin, a schistosomicidal chalcone from Piper aduncum L. (Piperaceae) that inhibits Schistosoma mansoni ATP diphosphohydrolase. Phytomedicine. 2015;22(10):921-8

12. Goncalves LM, Valente IM, Rodriques JA. An overview on cardamonin. J Med Food. 2014;17(6):633-40

13. Niu P, Shi D, Zhang S, Zhu Y, Zhou J. Cardamonin enhances the antiproliferative effect of cisplatin on ovarian cancer. Oncol Lett. 2018;15(3): 3991-7.

14. Niu PG, Zhang YX, Shi DH, Liu Y, Chen YY, Deng J. Cardamonin inhibits metastasis of Lewis lung carcinoma cells by decreasing mTOR activity. PLoS One. 2015:10(5):e0127778.

15. Xue ZG, Niu PG, Shi DH, Liu Y, Deng J, Chen YY. Cardamonin inhibits angiogenesis by mTOR Downregulation in SKOV3 cells. Planta Med. 2016; $82(1-2): 70-5$.
16. Shi D, Niu P, Heng X, Chen L, Zhu Y, Zhou J. Autophagy induced by cardamonin is associated with mTORC1 inhibition in SKOV3 cells. Pharmacol Rep. 2018;70(5):908-16

17. Tang Y, Fang Q, Shi D, Niu P, Chen Y, Deng J. mTOR inhibition of cardamonin on antiproliferation of A549 cells is involved in a FKBP12 independent fashion. Life Sci. 2014:99(1-2):44-51.

18. Heng XJ, Shi DH, Niu PG, Deng J, Deng JH. Study on the inhibitory effect of Cardamonin on ovarian Cancer SKOV3 cells by regulation of autophagy. Prog Modern Biomed. 2014;14(4):663-7.

19. Niu P, Zhang Y, Shi D, Chen Y, Deng J. Cardamonin ameliorates insulin resistance induced by high insulin and high glucose through the mTOR and signal pathway. Planta Med. 2013;79(6):452-8.

20. Ganapathy-Kanniappan S, Geschwind JF. Tumor glycolysis as a target for cancer therapy: progress and prospects. Mol Cancer. 2013;12:152.

21. Muilenburg D, Parsons C, Coates J, Virudachalam S, Bold RJ. Role of autophagy in apoptotic regulation by Akt in pancreatic cancer. Anticancer Res. 2014:34(2):631-7.

22. Le XF, Mao W, Lu Z, Carter BZ, Bast RC, Jr. Dasatinib induces autophagic cell death in human ovarian cancer. Cancer 2010:116(21):4980-4990.

23. Xie X, Bartholomeusz C, Ahmed AA, Kazansky A, Diao L, Baggerly KA, et al. Bisphosphorylated PEA-15 sensitizes ovarian cancer cells to paclitaxel by impairing the microtubule-destabilizing effect of SCLIP. Mol Cancer Ther. 2013;12(6):1099-111.

24. Kimmelman AC. The dynamic nature of autophagy in cancer. Genes Dev. 2011;25(19):1999-2010.

25. Hu XJ, Xie MY, Kluxen FM, Diel P. Genistein modulates the anti-tumor activity of cisplatin in MCF-7 breast and HT-29 colon cancer cells. Arch Toxicol. 2014:88(3):625-35.

26. Wang YF, Li T, Tang ZH, Chang LL, Zhu H, Chen XP, et al. Baicalein triggers autophagy and inhibits the protein kinase $\mathrm{B} / \mathrm{mammalian}$ target of Rapamycin pathway in hepatocellular carcinoma HepG2 cells. Phytother Res. 2015:29(5):674-9.

27. Dunlop EA, Tee AR. mTOR and autophagy: a dynamic relationship governed by nutrients and energy. Semin Cell Dev Biol. 2014;36:121-9.

28. Priebe A, Tan L, Wahl H, Kueck A, He G, Kwok R, et al. Glucose deprivation activates AMPK and induces cell death through modulation of Akt in ovarian cancer cells. Gynecol Oncol. 2011;122(2):389-95.

29. Xu XD, Shao SX, Jiang HP, Cao YW, Wang YH, Yang XC, et al. Warburg effect or reverse Warburg effect? A review of cancer metabolism. Oncol Res Treat. 2015:38(3):117-22.

30. Cecconi S, Mauro A, Cellini V, Patacchiola F. The role of Akt signalling in the mammalian ovary. Int J Dev Biol. 2012;56(10-12):809-17.

31. Gwak H, Haegeman G, Tsang BK, Song YS. Cancer-specific interruption of glucose metabolism by resveratrol is mediated through inhibition of Akt/ GLUT1 axis in ovarian cancer cells. Mol Carcinog. 2015;54(12):1529-40.

32. Mi C, Ma J, Shi H, Li J, Wang F, Lee JJ, et al. 4',6-dihydroxy-4methoxyisoaurone inhibits the HIF-1alpha pathway through inhibition of Akt/mTOR/p70S6K/4E-BP1 phosphorylation. J Pharmacol Sci. 2014;125(2): 193-201.

33. Jin Z, Gu J, Xin X, Li Y, Wang H. Expression of hexokinase 2 in epithelial ovarian tumors and its clinical significance in serous ovarian cancer. Eur J Gynaecol Oncol. 2014;35(5):519-24

34. Li J, Liu T, Zhao L, Chen W, Hou H, Ye Z, et al. Ginsenoside 20(S)Rg3 inhibits the Warburg effect through STAT3 pathways in ovarian cancer cells. Int J Oncol. 2015:46(2):775-81.

35. Allison SJ, Knight JR, Granchi C, Rani R, Minutolo F, Milner J, et al. Identification of LDH-A as a therapeutic target for cancer cell killing via (i) p53/NAD(H)-dependent and (ii) p53-independent pathways. Oncogene. 2014;3:e102.

36. Du GJ, Song ZH, Lin HH, Han XF, Zhang S, Yang YM. Luteolin as a glycolysis inhibitor offers superior efficacy and lesser toxicity of doxorubicin in breast cancer cells. Biochem Biophys Res Commun. 2008:372(3):497-502.

37. Zhang J, Wang Z, Zhang J, Zuo G, Li B, Mao W, et al. Rapamycin attenuates endothelial apoptosis induced by low shear stress via mTOR and sestrin1 related redox regulation. Mediat Inflamm. 2014;2014:769608.

38. Lee SC, Marzec M, Liu X, Wehrli S, Kantekure K, Ragunath PN, et al. Decreased lactate concentration and glycolytic enzyme expression reflect inhibition of mTOR signal transduction pathway in B-cell lymphoma. NMR Biomed. 2013;26(1):106-14

39. Laplante M, Sabatini DM. mTOR signaling in growth control and disease. Cell. 2012;149(2):274-93. 
40. Gao JL, Chen YG. Natural compounds regulate glycolysis in hypoxic tumor microenvironment. Biomed Res Int. 2015;2015:354143.

41. Duvel K, Yecies JL, Menon S, Raman P, Lipovsky Al, Souza AL, et al, Activation of a metabolic gene regulatory network downstream of mTOR complex 1. Mol Cell. 2010;39(2):171-83.

42. Malm SW, Hanke NT, Gill A, Carbajal L, Baker AF. The anti-tumor efficacy of 2-deoxyglucose and D-allose are enhanced with p38 inhibition in pancreatic and ovarian cell lines. J Exp Clin Cancer Res. 2015;34(1):31.

43. Alayev A, Holz MK. mTOR signaling for biological control and cancer. J Cell Physiol. 2013;228(8):1658-64.

44. Hardie DG, Ross FA, Hawley SA. AMPK: a nutrient and energy sensor that maintains energy homeostasis. Nat Rev Mol Cell Biol. 2012;13(4):251-62.

45. Saito Y, Nakada D. The role of the Lkb1/AMPK pathway in hematopoietic stem cells and leukemia. Crit Rev Oncog. 2014;19(5):383-97.

Ready to submit your research? Choose BMC and benefit from:

- fast, convenient online submission

- thorough peer review by experienced researchers in your field

- rapid publication on acceptance

- support for research data, including large and complex data types

- gold Open Access which fosters wider collaboration and increased citations

- maximum visibility for your research: over $100 \mathrm{M}$ website views per year

At BMC, research is always in progress.

Learn more biomedcentral.com/submissions 